\title{
Spinal somatosensory evoked potentials in hereditary spastic paraplegia*
}

\author{
P K THOMAS, J G R JEFFERYS, $\dagger$ I S SMITH, \\ A N D D L O U L A K A K I S \\ From the Department of Neurological Science, Royal Free Hospital, London
}

SUMMARY Cervical somatosensory evoked potentials elicited by median nerve stimulation were recorded from 18 cases of hereditary spastic paraplegia. Motor and sensory nerve conduction in the median nerve was normal in each. In one third of the patients no spinal evoked potential was detectable. In the remainder the amplitude of the evoked potential was reduced in comparison with a control series; the latency was not significantly different. These changes suggest that a selective degeneration of the centrally directed axons derived from the dorsal root ganglion cells occurs in this disorder. The findings are discussed in relation to previous reports on the pathological appearances.

This study was prompted by the observation that in patients with hereditary spastic paraplegia with associated sensory loss, usually of posterior column type, sensory nerve action potentials are normal (Thomas, unpublished). This suggested that the site of the lesion responsible for the sensory changes lies within the central nervous system. Fibre degeneration is known to be present within the posterior columns in hereditary spastic paraplegia. ${ }^{1-4}$ In order to explore the integrity of the centrally directed axons of the primary sensory neurons, it was therefore decided to examine spinal somatosensory evoked responses in patients with this condition. The present report records the results of a study on 18 patients.

\section{Material}

The observations were made on 12 male and six female patients with hereditary spastic paraplegia. They were

* Presented at a meeting of the Association of British Neurologists held in London in April, 1980.

†Present address: Institute of Neurology, Queen Square, London WC1N 3BG.

Address for reprint requests: Professor PK Thomas, Department of Neurological Science, Royal Free Hospital, London NW3 2QG.

Accepted 10 December 1980 derived from 12 families in which the inheritance was autosomal dominant in seven and of probable autosomal recessive pattern in four. In one of the latter families there were four affected siblings born to unaffected first cousin parents. Only one of the affected individuals in this family consented to evoked potential recordings. There were no other instances of consanguinity. One single case lacking a family history was included (case 2), but the diagnosis seemed probable on clinical grounds.

Recordings were also made on 10 healthy subjects who ranged in age from 22 to 53 years. Seven were male and three female.

\section{Methods}

The technique described by Matthews et $a l^{5}$ was adopted. The right median nerve was stimulated at the wrist through bipolar electrodes with $200 \mu$ s square wave pulses at four times the threshold for sensation at a rate of 3 per second, using a Devices isolated stimulator. Recordings were made from the midline of the neck posteriorly with disc electrodes just rostral to the spine of the seventh cervical vertebra (Cv7 electrode) and at the skull base ( $\mathrm{Cv} 2$ electrode). A reference electrode was placed in the midline over the anterior part of the scalp (FZ site in 10-20 system) and an earth in the midline just posterior to the vertex. Skin resistance was less than $5 \mathrm{k} \Omega$, usually $1-2 \mathrm{k} \Omega$. The potentials were amplified by a Devices amplifier with filters set to $2 \cdot 5 \mathrm{kHz}$ low pass, $0.16 \mathrm{~Hz}$ 
high pass. 256 sweeps were averaged by a Datalab DL4000 averager and the measurements made from photographs. The observations were obtained from at least three runs to ensure that any response was consistent.

\section{Results}

Motor and sensory nerve condition was examined in the right median nerve at the time of the recording. Motor conduction velocity over the forearm, recording from abductor pollicis brevis, was within normal limits in all the patients $\left(55 \cdot 5 \pm 5 \cdot 3 \mathrm{~m} \mathrm{~s}^{-1}\right.$, range $\left.49-66 \mathrm{~m} \mathrm{~s}^{-1}\right)$ as was the distal motor latency $(3 \cdot 7 \pm 0.38 \mathrm{~ms}, 3.2-4.0 \mathrm{~ms})$. Sensory conduction was also normal in all instances when assessed by stimulation of the digital nerves of the index finger through ring electrodes and percutaneous recording over the median nerve at the wrist (amplitude 13.9 $\pm 3 \cdot 2 \mu \mathrm{V}, 10$ $21 \mu \mathrm{V}$; latency to negative peak $3.1 \pm 0.5 \mathrm{~ms}$, 2.9-4.0 ms).

For the spinal somatosensory evoked potentials, the amplitude measured to the nearest $0.5 \mu \mathrm{V}$, and latency of the main negative (N13) peak obtained from the Cv7 electrode are shown in the table. No potential was detectable in six patients. In the remainder, the mean amplitude was $1.25 \pm 0.69 \mu \mathrm{V}$. This was significantly less $(\mathrm{p}<0.001)$ than the mean value for the control subjects, which was $3 \cdot 0 \pm 0.83 \mu \mathrm{V}$. The latency of the N13 peak, which was $(13 \cdot 2 \pm 0.94 \mathrm{~ms})$ in the control subjects, was the same $13 \cdot 2 \pm 0.81 \mathrm{~ms}$ in those patients in whom the potential was obtained.
When the responses were compared in those instances where two members were examined from a single family, they were seen to be concordant, that is they were either totally unrecordable or obtainable but of reduced amplitude, in both members of the pair. Sensory impairment was not detected in the upper limbs in any of the patients, but was evident in the lower limbs in three instances. The numbers are insufficient to attempt any correlation with the electrophysiological findings. The tendon reflexes were obtainable, and usually exaggerated, in both the upper and lower limbs in all patients except case 18, in whom the ankle jerks were absent. Both plantar responses were extensor in every patient.

\section{Discussion}

Hereditary spastic paraplegia was first clearly delineated by Strümpell. ${ }^{6}$ Subsequent studies have demonstrated that the disorder is genetically heterogeneous: there exist cases in which the condition is present in a relatively "pure" form and others where there is a variety of other coexistent features. Holmes and Shaywitz ${ }^{7}$ reviewed the world litrature and, employing strict diagnostic criteria, accepted 104 reported families with the "pure" form of the disease. Of these, inheritance was autosomal dominant in $70 \%$. It is possible that early and late onset forms exist in both the autosomal dominant and recessive groups. ${ }^{8} \mathrm{X}$ linked inheritance is extremely rare. The present cases were all examples of the pure form of the

Table Clinical details, and amplitudes and latencies of cervical $(C v 7$ recording) somatosensory evoked responses in 18 patients with hereditary spastic paraplegia

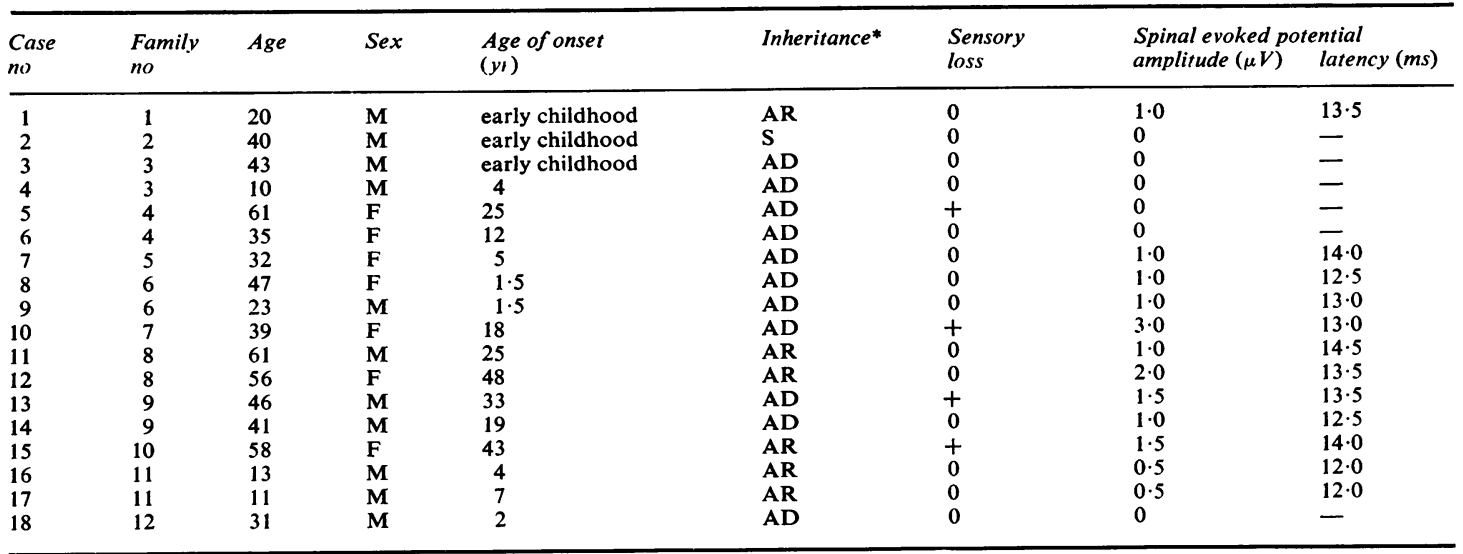

*AD autosomal dominant; AR autosomal recessive; $\mathrm{S}$ single case. 
disease, apart from cases 11 and 12 who displayed disordered eye movements and Case 18 who developed some distal amyotrophy in the limbs later in the course of his illness.

A previous study by McLeod $^{9}$ has documented preservation of sensory nerve action potentials and this was confirmed here for the upper limbs. The new observation in the present study is that despite preserved sensory nerve conduction, the spinal somatosensory evoked responses in hereditary spastic paraplegia may be undetectable and that when they are obtainable, they tend to be of reduced amplitude. The N13 somatosensory spinal evoked potentials are usually considered to reflect presynaptic and postsynaptic potentials arising in the dorsal horn. ${ }^{10} \mathrm{~A}$ neuropathological basis for this is suggested by the report by Behan and $\mathrm{Maia}^{4}$ who recorded fibre degeneration in the posterior columns in patients with the pure form of hereditary spastic paraplegia but showed preservation of the posterior spinal roots. Degeneration in the posterior columns has also been noted by Strümpell, ${ }^{1}$ Schwarz and $\mathrm{Liu}^{2}$ and Schwartz. ${ }^{3}$ It is not yet established whether the intramedullary portion of the fibres of the spinal roots that reach the posterior horns, and which are likely to be involved in the generation of the spinal somatosensory evoked responses, are also implicated in the degenerative process.

These observations suggest that degeneration of the centrally directed processes of the primary sensory neurons may occur within the posterior columns, but that the posterior roots outside the cord and the peripherally directed axons in the peripheral nerves remain intact.

The concept of a selective distal degeneration of axons had its origins in the neuropathological studies of Mott ${ }^{11}$ at the end of the last century on Friedreich's ataxia and other disorders and by Greenfield $^{12}$ in his monograph on the spinocerebellar degenerations. Cavanagh ${ }^{13}$ formulated the notion of a "dying back" of axons towards the cell body more precisely. Subsequently Spencer and Schaumburg ${ }^{15}$ pointed out that the changes represented a multifocal distal but preterminal degeneration of axons that often simultaneously involved the peripheral and central nervous system. In particular, both the centrally and peripherally directed axons from the primary sensory neurons were affected, so that the term centralperipheral distal axonopathy was introduced. ${ }^{15}$ In subacute myelo-optic neuropathy related to clioquinol intoxication, it is known that degeneration occurs in the rostral portions of the posterior columns and the caudal portion of the corticospinal pathways in the spinal cord, ${ }^{15}$ suggesting a "dying-back" process. Despite the fact that patients have symptoms suggestive of a peripheral neuropathy, the evidence for the occurrence of degeneration in the peripheral nerves is slender. The suggestion was therefore made (Thomas, unpublished) that there was a selective distal axonopathy affecting only the central processes of the primary sensory neurons, together with other CNS pathways such as the corticospinal tracts and the visual pathways. This was later shown to be the case for experimental clioquinol neurotoxicity in the $\operatorname{dog} .{ }^{17}$ It seems likely that hereditary spastic paraplegia provides a further instance of this type of effect.

The reason for the distal situation of the lesion in the "dying-back" neuropathies is uncertain, but in toxic and deficiency neuropathies Schoental and Cavanagh ${ }^{18}$ proposed that cofactor inactivation in the axon may be responsible. From observations on certain toxic neuropathies Spencer et $a^{19}$ suggested that glycolytic enzyme inactivation may be involved. Enzyme synthesis takes place in the cell body and therefore replenishment will be least effective distally. The structural differences between the various instances of dyingback neuropathy that have been described, and their different behaviour in relation to superimposed experimental nerve injury, ${ }^{20}$ suggest that the target system within the axons is likely to be different in those conditions that are structurally dissimilar. Isoniazid gives rise to a distal axonopathy that particularly affects the peripheral nervous system. The explanation may be that this substance crosses the blood-brain barrier rather poorly. ${ }^{18}$ The mechanism for a selective CNS distal axonopathy is at present obscure. If dis'al axonopathies result from a depletion or inherited deficiency of enzymes involved in the maintenance of structural integrity, it is conceivable that different enzyme systems are present in axons within the central and peripheral nervous systems.

In contrast to hereditary spastic paraplegia, Friedreich's ataxia gives rise to degeneration of both the centrally and peripherally directed axons of the larger dorsal root ganglion cells. ${ }^{21}$ The peripheral sensory nerve action potentials are therefore diminished or lost $^{22}$ and spinal somatosensory evoked potentials are reduced in amplitude or undetectable. ${ }^{10}$ Parietal somatosensory evoked potentials in this condition are delayed. ${ }^{10}$ In subacute combined degeneration of the cord from vitamin $B_{12}$ deficiency, there is some evidence, derived from evoked potential recording, that the centrally directed axons of the dorsal root ganglion 
cells are affected earlier than the peripheral axons. ${ }^{23}$

We are indebted to Dr Alex Siafakos for his assistance in the earlier part of this study and to Drs P B Croft, A E Harding and R A C Hughes for referring patients. Financial support from the Friedreich's Ataxia Group is gratefully acknowledged. We also wish to thank $\mathrm{Mr}$ John Muddle for technical assistance and Drs Martın Halliday and David Small for helpful discussion.

\section{References}

1 Strümpell A. Über eine bestimmte Form der primären combinierten Systemerkrankung des Ruckenmarks. Arch Psychiatr Nervenkr 1886; 17:227-38.

2 Schwarz GA. Hereditary (familial) spastic paraplegia. Arch Neurol Psychiatr (Chicago) 1952; 68:655-82.

3 Schwarz GA, Liu CN. Hereditary familial spastic paraplegia. Further clinical and pathologic observations. Arch Neurol Psychiatr (Chicago) 1956; 75:144-62.

4 Behan WMH, Maia M. Strümpell's familial spastic paraplegia: genetics and neuropathology. J Neurol Neurosurg Psychiatry 1974; 37:8-20.

5 Matthews WB, Beauchamp M, Small DG. Cervical somatosensory evoked responses in man. Nature 1974; 252:230-32.

6 Strümpell A. Beiträge zur Pathologie des Ruckenmarks. Arch Psychiatr Nervenkr 1880; 10:676717.

7 Holmes GL, Shaywitz BA. Strümpell's pure familial spastic paraplegia: case study and review of the literature. J Neurol Neurosurg Psychiatry 1977; 40:1003-8.

8 Haldane JBS. The relative importance of principal and modifying genes in determining some human diseases. J Genet 1940; 41:149-51.

9 McLeod JG, Morgan JA, Reye C. Electrophysiological studies in familial spastic paraplegia. $J$ Neurol Neurosurg Psychiatry 1977; 40:611-15.

10 Jones SJ, Baraitser M, Halliday AM. Peripheral and central somatosensory nerve conduction defects in Friedreich's ataxia. J Neurol Neurosurg Psychiatry 1980; 43:495-503.
11 Mott FW. Case of Friedreich's disease with autopsy and systematic microscopical examination of the nervous system (from the Pathology Laboratory, London County Asylums). Arch Neurol Psychiat 1907; 3:180-200.

12 Greenfield JG. The Spino-cerebellar Degenerations. Oxford: Blackwell Scientific Publications, 1954.

13 Cavanagh JB. The significance of the "dyingback" process in experimental and human neurological disease. Int Rev Exp Biol 1964; 3:219-67.

14 Spencer PS, Schaumburg HH. Ultrastructural studies of the dying-back process. III. The evolution of experimental peripheral giant axonal degeneration. J Neuropath Exp Neurol 1977; 36: 276-99.

15 Spencer PS, Schaumburg HH. Central-peripheral distal axonopathy - the pathology of dying-back polyneuropathies. Prog Neuropath 1976; 3:253-95.

16 Shiraki $\mathrm{H}$. The neuropathology of subacute myelooptico-neuropathy, SMON, in humans. Jpn J Med Sci Biol 1975; 28: Suppl. 101.

17 Krinke G, Schaumburg H, Spencer PS, Thomann $P$, Hess R. Clioquinol and 2,5 hexanedione produce different types of distal exonopathy: a comparative experimental study in the dog. Acta Neuropathol (Berlin) 1979; 47:213-21.

18 Schoental R, Cavanagh JB. Mechanisms involved in the "dying-back" process-an hypothesis implicating coenzymes. Neuropath Appl Neurobiol 1977; 3:145-57.

19 Spencer PS, Sabri MA, Schaumburg HH, Moore CL. Hypothesis: does a defect of energy metabolism in the nerve fibre underlie axonal degeneration in polyneuropathies. Ann Neurol 1979; 5:501-7.

20 Cavanagh JB, Gysbers MF. "Dying-back" above a nerve ligature produced by acrylamide. Arch Neuropathol 1980; 51:169-77.

21 Hughes JT, Brownell B, Hewer RL. The peripheral sensory pathway in Friedreich's ataxia. Brain 1968; 91:803-18.

22 McLeod JG. An electrophysiological and pathological study of peripheral nerves in Friedreich's ataxia. J Neurol Sci 1971; 12:333-49.

23 Fine EJ, Hallett M. Neurophysiological study of subacute combined degeneration. J Neurol Sci 1980; 45:331- - 